\title{
Integration of the Cloud Environment in E-learning Systems
}

\author{
Karim Dahdouh, Lahcen Oughdir, Ahmed Dakak \\ LSI, Department of Mathematics, Physics and Informatics \\ University of Sidi Mohamed Ben Abdellah, FPT,Taza, Morocco \\ Karim.dahdouh@usmba.ac.ma, ahcen.oughdir@usmba.ac.ma,ahmed.dakak@usmba.ac.ma
}

\begin{abstract}
Nowadays, e-learning systems have known a major revolution, especially with the emergence of new information and communication technologies and the enormous growth in the number of learners, educational content and resources. which causes many challenges in terms of optimizing resources such as compute, storage and communication, highlighting the need to use a model that meets evolving requirements and cost control. In this context, cloud computing is proving to be a promising model because of its permanent scalability and the efficient use of resources. This paper presents the characteristics of current e-learning systems, then analyzes the concept of cloud computing and describes the architecture of it by combining the features of e-learning. We propose an approach of using and harnessing Cloud computing services in e-learning systems to build an e-learning environment based on cloud computing.
\end{abstract}

Keywords : E-learning, Cloud Computing, Cloud services, e-learning cloud, e- learning based cloud, Learner, laas,Saas, Paas.

\section{Introduction}

At present, most of the conventional education forms are becoming not being suitable for requirements of social progress and educational development and not being able to catch up with the changes of learning demand Which continues to increase especially with the emergence of new information technologies and the enormous growth in the number of learners, The educational content, the services that can be offered and the resources available, the dimensions of the e-learning system grow at an exponential rate. Challenges With regard to optimization of resource requirements, storage and communication requirements and the processing of requests for simultaneous competition, it is necessary to use a platform that meets the evolving requirements and the control costs.

However, in traditional web-based e-learning mode, system construction and maintenance are located in interior of educational institutions or enterprises, which results in a lot of problems existed, such as a lot of investment needed, but without capital gains to return, without development potential and staying power. Cloud computing is becoming an attractive technology due to its dynamic scalability and effective usage of the resources; it can be utilized under circumstances where the availability of resources is limited. 
Karim Dahdouh, Lahcen Oughdir, Ahmed Dakak; Integration of the Cloud Environment in E-learning Systems. Transactions on Machine Learning and Artificial Intelligence, Vol 5 No 4 August (2017); pp: 55-65

The new information technologies have changed the way of teaching and learning. Being the state of the art in education means that the institutions providing e-learning should offer new opportunities for selfregulated e-learning consistent with the new expectations and needs of nowadays digital learners.

Combining the features of traditional learning systems with the cloud-based ones will give the organizations a powerful tool that is cost effective, easy to maintain, secure and engaging learners and teachers. But until now the research applying cloud computing to e-learning is not significantly reported. In order to give a full play for the advantages of cloud computing, in this paper, we tried to attach cloud computing to e-learning, build an e-learning cloud, and made an active research and exploration for it.

\section{Cloud Computing}

\subsection{General context}

The remarkable development of cloud computing in recent years is increasingly sparking the interest of Internet and IT users seeking to derive the greatest benefit from the services and applications available on line via the web in service-on-demand mode with per-usage billing.

Cloud Computing is a new paradigm to organize and manage ICT resources. There are various definitions of cloud computing, one of which is the definition according to The National Institute of Standards and Technology (NIST) which defines cloud computing as "model for enabling convenient, on-demand network access to a shared pool of configurable computing resources (e.g., networks, servers, storage, applications, and services) that can be rapidly provisioned and released with minimal management effort or service provider interaction" [26].

In this context Praveena and Betsy [17] have described the application of Cloud in universities. Delic and Riley [18] assessed the current state of enterprise knowledge management and how it would turn into a more global, dependable and efficient infrastructure with Cloud computing. They have discussed architecture as well as applications. Cloud computing attributes can be visualized from the following comparison:

Traditional Computing Cloud Computing

\begin{tabular}{|c|c|}
\hline $\begin{array}{l}\text { - Buy Assets } \\
\text { - Build Technical Architecture }\end{array}$ & $\begin{array}{l}\text { - Buy Service } \\
\text { - Architecture included }\end{array}$ \\
\hline $\begin{array}{l}\text { - Payfor Assets } \\
\text { - Administrative Overhead }\end{array}$ & $\begin{array}{l}\text { - Pay for Use } \\
\text { - Reduced Admin Function }\end{array}$ \\
\hline $\begin{array}{l}\text { - Internal Networks } \\
\text { - Corporate Desktop }\end{array}$ & $\begin{array}{l}\text { - Over the Internet } \\
\text { - Any device }\end{array}$ \\
\hline $\begin{array}{l}\text { - Single-tenant, non-shared } \\
\text { - Static }\end{array}$ & $\begin{array}{l}\text { - Multi-tenant. Scalable. Elastic. } \\
\text { - Dynamic }\end{array}$ \\
\hline $\begin{array}{l}\text { - Costly, Lengthy deployments } \\
\text { - Land and expand staffing }\end{array}$ & $\begin{array}{l}\text { - Reduced deployments time } \\
\text { - Fast ROI }\end{array}$ \\
\hline
\end{tabular}

Figure. 1 .Comparison between traditional computer and cloud 


\subsection{Cloud computing deployment models}

The principle of the cloud is to pool the resources of infrastructures and services in order to optimize their use and to realize economies of scale. According to the National Institute of Standards and Technology (NIST) [26], four of the most common cloud deployment models are:

- $\quad$ Public cloud: The cloud infrastructure is provisioned for open use by the general public. It may be owned, managed, and operated by a business, academic, or government organization, or some combination of them. It exists on the premises of the cloud provider.

- $\quad$ Private cloud: The cloud infrastructure is provisioned for exclusive use by a single organization comprising multiple consumers (e.g., business units). It may be owned, managed, and operated by the organization, a third party, or some combination of them, and it may exist on or off premises.

- $\quad$ Community cloud: The cloud infrastructure is provisioned for exclusive use by a specific community of consumers from organizations that have shared concerns (e.g., mission, security requirements, policy, and compliance considerations). It may be owned, managed, and operated by one or more of the organizations in the community, a third party, or some combination of them, and it may exist on or off premises.

- Hybrid cloud: The cloud infrastructure is a composition of two or more distinct cloud infrastructures (private, community, or public) that remain unique entities, but are bound together by standardized or proprietary technology that enables data and application portability (e.g., cloud bursting for load balancing between clouds).

A computing environment can use a multitude of clouds, whether public, private, community or hybrid, as shown in Fig. 2.

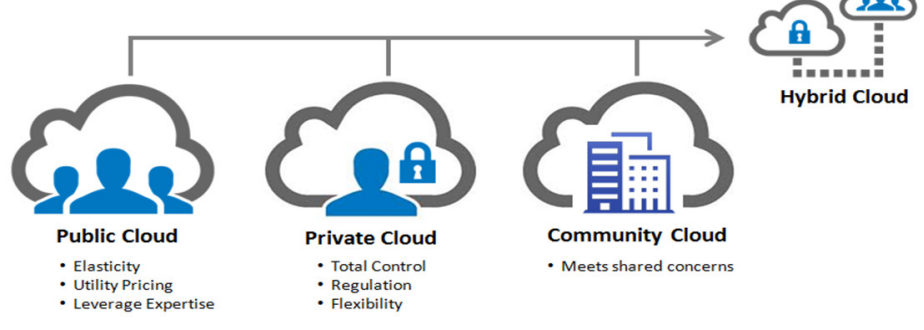

Figure 2 .Cloud Computing deployment models

\subsection{Cloud computing services models}

Cloud service models describe how cloud services are made available to clients. Most fundamental service models include a combination of laaS (infrastructure as a service), PaaS (platform as a service), and SaaS (software as a service). These service models may have synergies between each other and be interdependent - for example, PaaS is dependent on laaS because application platforms require physical infrastructure Fig. 3. 


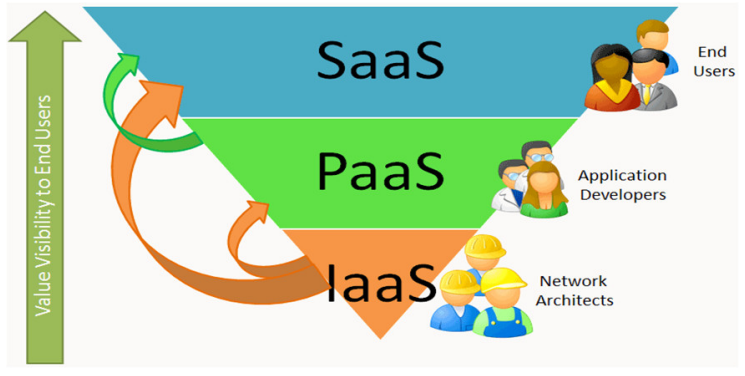

Figure 3 .Cloud computing services models

Infrastructure as a Service (laaS): The capability provided to the consumer is to provision processing, storage, networks, and other fundamental computing resources where the consumer is able to deploy and run arbitrary software, which can include operating systems and applications. The consumer does not manage or control the underlying cloud infrastructure but has control over operating systems, storage, and deployed applications; and possibly limited control of select networking components (e.g., host firewalls).

Software as a Service (SaaS): The capability provided to the consumer is to use the provider's applications running on a cloud infrastructure. The applications are accessible from various client devices through either a thin client interface, such as a web browser (e.g., web-based email), or a program interface. The consumer does not manage or control the underlying cloud infrastructure including network, servers, operating systems, storage, or even individual application capabilities, with the possible exception of limited user-specific application configuration settings.

Platform as a Service (PaaS): The capability provided to the consumer is to deploy onto the cloud infrastructure consumer-created or acquired applications created using programming languages, libraries, services, and tools supported by the provider. The consumer does not manage or control the underlying cloud infrastructure including network, servers, operating systems, or storage, but has control over the deployed applications and possibly configuration settings for the application-hosting environment.

\section{From traditional e-learning network to cloud e-learning}

E-learning is an Internet-based learning process, using Internet technology to design, implement, select, manage, support and extend learning, which will not replace traditional education methods, but will greatly improve the efficiency of education. As e-learning has a lot of advantages like flexibility, diversity, measurement, opening and so on, it will become a primary way for learning in the new century as in Fig. 4 [27]. 


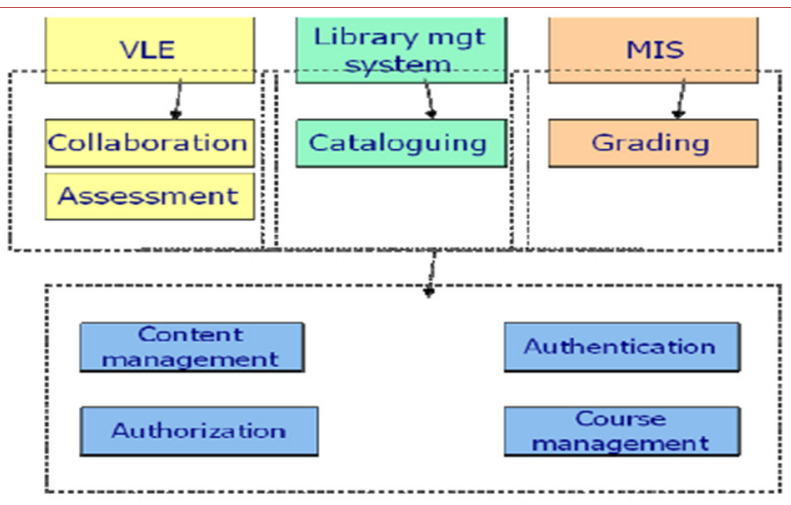

Figure 4. Architecture of a simplified Learning System

Mendez [19] illustrates that in traditional web-based learning mode, system construction and maintenance are located inside the educational institutions or enterprises, which led to a lot of problems, such as significant investment needed but without capital gains for them, which leads to a lack of development potential. In contrast, cloud based e-learning model introduces scale efficiency mechanism, i.e. construction of e-learning system is entrusted to cloud computing suppliers, which can make providers and users to achieve a win-win situation. The cloud-based environment supports the creation of new generation of e-learning systems, able to run on a wide range of hardware devices, while storing data inside the cloud.

Ouf [20] has presented an innovative e-learning ecosystem based on cloud computing and Web 2.0 technologies. The article analyses the most important cloud-based services provided by public cloud computing environments such as Google App Engine, Amazon Elastic Compute Cloud (EC2) or Windows Azure, and highlights the advantages of deploying E-Learning 2.0 applications for such an infrastructure. The authors also identified the benefits of cloud-based E-Learning 2.0 applications (scalability, feasibility, or availability) and underlined the enhancements regarding the cost and risk management.

Chandran [21] focused on current e-learning architecture model and on issues in current e-learning applications. The article presents the Hybrid Instructional Model as the blend of the traditional classroom and online education and its customization for e-learning applications running on the cloud computing infrastructure. The authors underline the e-learning issues, especially the openness, scalability, and development/customization costs. The existing e-learning systems are not dynamically scalable and hard to extend - integration with other e-learning systems is very expensive. The article proposed the hybrid cloud delivery model that can help in fixing the mentioned problems.

In this article a new paradigm is highlighted in educational area by introducing the cloud computing in order to increase the scalability, flexibility and availability of e-learning systems. The authors have evaluated the traditional e-learning networking model, with its advances and issues, and the possibility to move the e-learning system out of schools or enterprises, inside a cloud computing infrastructure. The separation of entity roles and cost effectiveness can be considered important advantages. The institutions will be responsible for the education process, content management and delivery, and the vendor takes care of system construction, maintenance, development and management. The e-learning system can be scaled, both horizontally and vertically, and the educational organization is charged according to the number of used servers that depends on the number of students as in Fig. 5 [24]. 


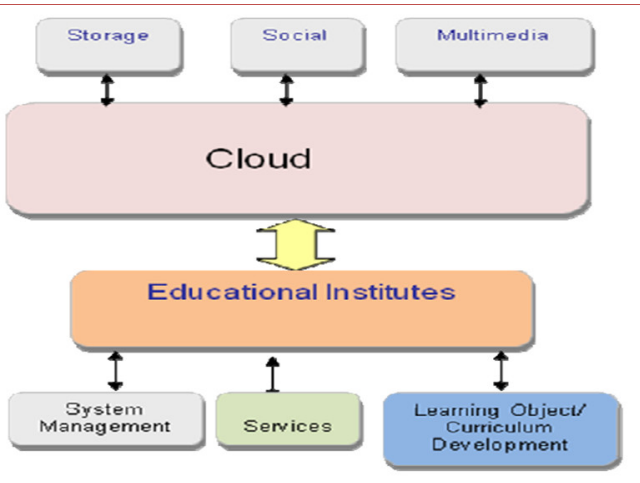

Figure 5 . Modified E-learning System Architecture.

The e-learning cannot completely replace teachers; it is only an updating for technology, concepts and tools, giving new content, concepts and methods for education, so the roles of teachers cannot be replaced. The teachers will still play leading roles and participate in developing and making use of elearning cloud. The blended learning strategy should improve the educational act. Moreover, the interactive content and virtual collaboration guarantee a high retention factor.

On the other hand, E-learning based cloud is a migration of cloud computing technology in the field of elearning, which is a future e-learning infrastructure, including all the necessary hardware and software computing resources engaging in e-learning. After these computing resources are virtualized, they can be afforded in the form of services for educational institutions, students and businesses to rent computing resources. E-learning based cloud approach is shown in Fig.6.

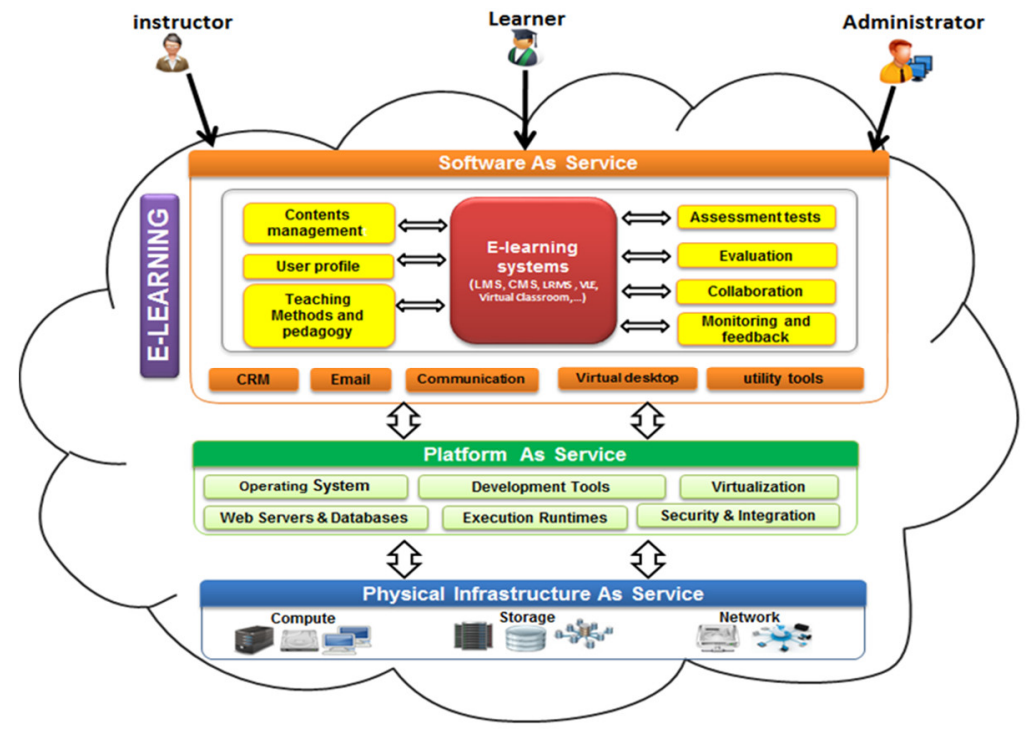

Figure 6 . E-learning based Cloud Approach.

The proposed e- learning cloud architecture can be divided into the following layers: Physical infrastructure layer as a dynamic and scalable physical host pool, platform as a service layer provides resources to build applications, Software as a service layer consist of complete applications that do not require development it that provides with content production, content delivery, virtual laboratory, collaborative learning, assessment and management features. 


\subsection{Infrastructure layer}

Infrastructure layer is composed of information infrastructure and teaching resources. Information infrastructure contains Internet/Intranet, system software, information management system and some common software and hardware; teaching resources is accumulated mainly in traditional teaching model and distributed in different departments and domain. This layer is located in the lowest level of cloud service middleware, the basic computing power like physical memory, CPU, memory is provided by the layer. Through the use of virtualization technology, physical server, storage and network form virtualization group for being called by upper software platform. The physical host pool is dynamic and scalable, new physical host can be added in order to enhance physical computing power for cloud middleware services. The following Fig. 7 depicts this in a clearer view [27].

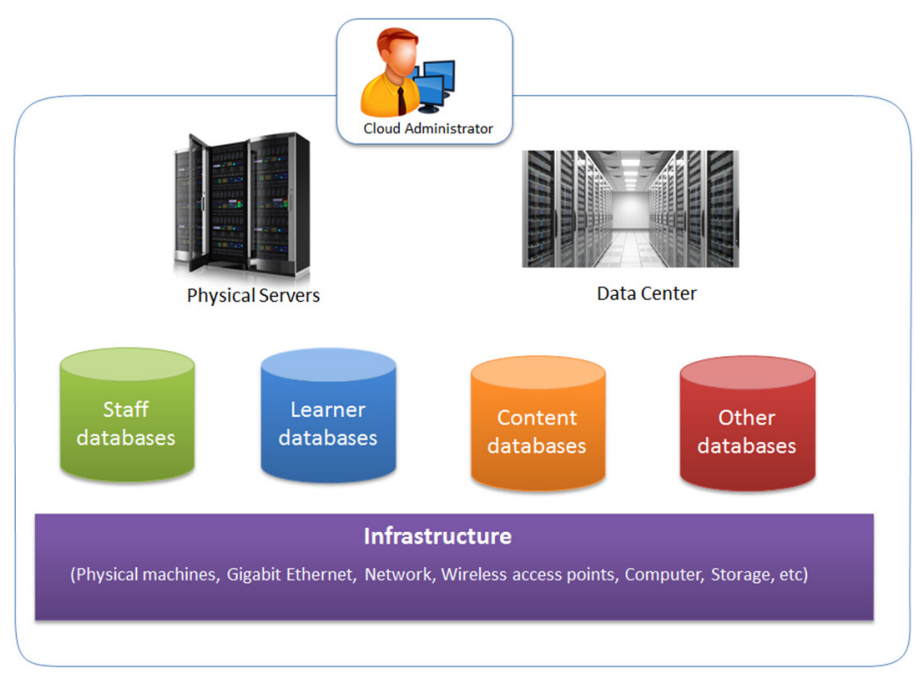

Figure. 7 . Proposed Infrastructure layer

\subsection{Platform as a service layer}

This layer is generally composed of operating system (Windows, UNIX, etc.), the development Tools, the execution runtimes, the virtualization, the web servers, the databases and the security.

The provider supplies a platform of software environments and application programming interfaces (APIs) that can be utilized in developing cloud applications. Naturally, the users of this class of systems are developers who use specific APIs or programing language to build, test, deploy, and tune their applications on the cloud platform.

At this layer customers do not manage their virtual machines, there is no need to manage an operating system, and it is the supplier who occupies these tasks. E-learning professionals merely create their own programs which are hosted by the platform services they are paying for.

\subsection{Software as a service layer}

The third and final layer of the cloud is Software as a Service, or Application as a service. This layer is the one that learner and tutor most likely to interact with in the learning process, and it is almost always accessible through a web browser. Any application hosted on a remote server that can be accessed over the Internet is considered a SaaS. 
Karim Dahdouh, Lahcen Oughdir, Ahmed Dakak; Integration of the Cloud Environment in E-learning Systems. Transactions on Machine Learning and Artificial Intelligence, Vol 5 No 4 August (2017); pp: 55-65

Software as a service layer is the specific applications of integration the teaching resources in the cloud computing model, including interactive courses and sharing the teaching resources. The interactive programs are mainly for the teachers, according to the learners and teaching needs, taken full advantage of the underlying information resources after finishing made, and the course content as well as the progress may at any time adjust according to the feedback, and can be more effectiveness than traditional teaching. Sharing of teaching resources include teaching material resources, teaching information resources (such as digital libraries, information centers), as well as the full sharing of human resources. This layer mainly consists of content production, educational objectives, Teaching Methods and pedagogy, content delivery technology, contents management, assessment and Monitoring and feedback.

In the classic e- learning model, teachers assign teaching tasks, conduct regular lectures, or train students skills. The students attend the online autonomous learning act and cooperative learning sessions, or accomplish teachers' assignments. But in the proposed architecture teachers also answer students' questions and offer essential teaching to major and difficult points. In addition, teachers can also use multimedia to enhance teaching content. Students work out their own learning plans, determining learning methods autonomously. They conduct on-line autonomous learning when they study each unit, finish its test via Internet and do some statistics to the test results. Teachers also encourage students to cooperate with each other to finish simple learning tasks or complex group-based projects. Through cooperative learning, students cannot only acquire knowledge, their team spirit and coordination will also be fostered, skills in dealing with people will be improved and abilities to express themselves will be enhanced. Thus the learning and teaching will be more interactive which is the demand of the age. The interactive mode of the proposed architecture is furnished in the Fig. 8 [27].

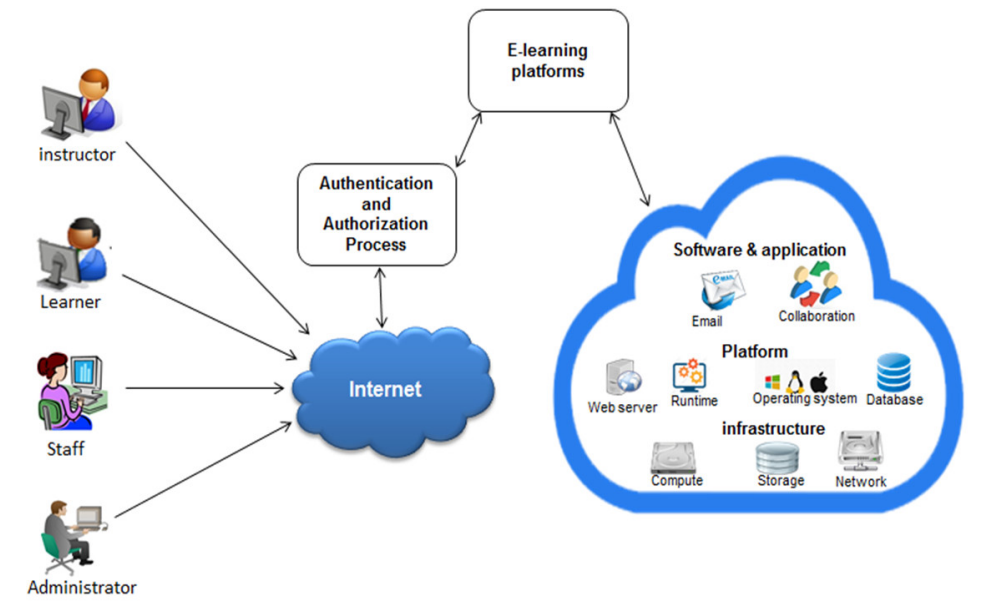

Figure 8 . Interactive mode of the proposed approach

\section{Expected benefit from E-learning based cloud}

There are several advantages of e-learning implementation of cloud computing technology, which include:

a) Powerful computing and storage capacity: Cloud based E-learning architecture locates the computing and data in a large number of distributed computers, the sea of clouds in the tens of thousands of computers to provide powerful computing power and huge data storage space, puts the "cloud" as a service available to students via the Internet. 
Transactions on Machine Learning and Artificial Intelligence Vol 5 No 4, Aug 2017

b) It lowers the cost: users need not to have high end configured computers to run e-learning applications. Through cloud they can run the applications through their mobile phones, PC, tablet PC with internet connection.as the data created is accessed in the cloud, the user need not to spend more money on storage devices for large memory in local machines. And organizations also need to pay for per use, so it's cheaper.

c) High availability: Through the integration of mass storage and high-performance computing power, this system can provide a higher quality of service. Cloud computing system can automatically detect the node failure and exclude it, do not affect the normal operation of the system.

d) High security: In the cloud computing model, data is storied intensively. Relying on one or more data center, the managers manage the unified data, allocate the resources, balance load, deploy the software, control security, and do the reliable real time monitoring, thus guarantee the users' data security to the greatest possible degree.

e) Virtualization: Virtualization is the most important characteristics of this type of architecture. Each application deployment environment and physical platform is not related. It is managed, expensed, migrated, and backup through virtualization platform. It put the underlying hardware, including servers, storage and networking equipment, comprehensive virtualization, in order to build a resources pool of shared, distributed on-demand.

f) Instant software updates: The software are automatically updated in cloud computing. So the users can get the updates instantly.

g) Improved compatibility with document formats: Since some file formats and fonts do not open properly in some PCs/mobile phones, the cloud powered E-learning applications do not have to worry about those kinds of problems. As the cloud based E-learning applications open the file from the cloud.

h) Benefits for students: Students get more advantage of e leaning based on cloud as they can enhance their skills by taking online courses, attending online exams, getting feedback from their instructor, and can send their assignments and projects online to their teachers.

i) Benefits for teachers: Teachers also get numerous benefits of cloud based e-learning. Teachers can prepare for online tests for students, interaction and better resources for students through content management, assessment tests, homework and projects undertaken by students, feedback and communication through the forum online.

The major advantage of the proposed approach is that it aims at providing easy access to costly software running on high performance processors to rural students at institutions which lack considerable facilities. Considerable investment would be required to implement this architecture, but the benefits would easily justify the cost.

\section{Conclusion and Future Work}

This paper proposes an approach for integrate cloud computing services in e-learning systems. The implementation of e-learning is now generally constructed separately by each institution. The deployment of e-learning platforms is costly because it takes the cost for provision of infrastructure, systems development, and hiring IT staff to maintain and enhance e-learning systems. Cloud computing is the most promising computing model using from last decade in distributed computing. With the implementation of e-learning in a cloud environment, educational institutions no longer have to pay for the provision of 
Karim Dahdouh, Lahcen Oughdir, Ahmed Dakak; Integration of the Cloud Environment in E-learning Systems.

Transactions on Machine Learning and Artificial Intelligence, Vol 5 No 4 August (2017); pp: 55-65

infrastructure because it has been provided by the cloud service provider and institutions that wish to use it only pay according to the usage. The aim of our work was to propose an approach which will be using the services of Cloud Computing in e-learning systems. Mainly, we have presented the characteristics of current e-learning systems, then we have analyzed the concept of cloud computing and describes the architecture of it by combining the features of e-learning, and finally we have discussed the expected benefits of the proposed approach. Future research will include a study regarding the implementation strategy for migration to the proposed approach based on cloud.

\section{REFERENCES}

[1] F. Jian, "Cloud computing based distance education outlook", China electronic education, 2009.10, Totally 273, pp.39-42.

[2] R. Hua, "Teaching Information System Based on Clou d Computing", Computer and Telecommunications, 2010.02, pp. 42-43.

[3] Y. Juan, S. Yi-xiang, "The Initial Idea of New Lear ning Society which Based on Cloud Computing", Modern Educational Techn ology, Vol.20, No.1, 2010, pp.14-17.

[4] T. Jian, F. Lijian, G. Tao, "Cloud computing-based Design of Network Teaching System", Journal of TaiYuan Urban Vocation al college, Mar. 2010, pp.159-160.

[5] Y. Zhongze, "The basic principles of cloud computin g and its impact on education", Satellite TV and Broadband Multimedia, 2010.6, pp.67-70.

[6] W. Xiaomei, J. Xiaoqiang, "Cloud computing on the Impact of Higher Education", Science \& Technology Information, 2010. 10, pp.397-398.

[7] Z. Zhong-ping, L. Hui-cheng, “The Development and Exploring of E- Learning System on Campus Network” , Journal of Shanxi Teacher' s University (Natural Science Edition), Vol .18, No.1, Mar. 2004, pp.36-40.

[8] W. Jianmin, “Campus Network's E-learning Mode”, New Curriculum Research, 2007.08, pp.84-86.

[9] Y. Wei, Y. Rong, "Research of an E-learning System Model Based on Agent", Computer Engineering and Applications, Nov. 2004, pp.156-158.

[10] A. Gladun, J. Rogushina, F. Garcı' a-Sanchez, R. Martı' nez-Be' jar, J. Toma' s Ferna' ndez-Breis, “An application of intelligent techniqu es andsemantic web technologies in e-learning environments", Expert Systems with Applications 36, 2009, 922-1931.

[11] Y. Li, S. Yang, J. Jiang, M. Shi, "Build grid-enab led large-scale collaboration environment in e-learning grid", Expe rt Systems with Applications 31,2006, 742-754.

[12] Z. Chengyun, "Cloud Security: The security risks of cloud computing, models and strategies", Programmer, May.2010, pp.71-73. 
Transactions on Machine Learning and Artificial Intelligence Vol 5 No 4, Aug 2017

[13] B. Hayes, "Cloud computing," Comm. Acm, vol. 51, no. 7, pp. 9- 11, 2008.

[14] E. Tuncay, "Effective use of Cloud computing in educational institutions," Procedia Social Behavioral Sciences, p. 938-942, 2010.

[15] R. Buyya, C.S. Yeo \& S.Venugopal, "Market-oriented Cloud computing: Vision, hype, and reality of delivering IT services as computing utilities," 10th leee Int. Conf. High Performance Comput. Comm., p. 5-13, 2009.

[16] M. Lijun, W.K. Chan \& T.H. Tse, "A tale of Clouds: Paradigm comparisons and some thoughts on research issues," leee Asia-pasific Services Comput. Conf., Apscca08, pp. 464-469, 2008.

[17] K. Praveena\& T. Betsy, "Application of Cloud Computing in Academia," lup J. Syst. Management, vol. 7, no. 3, pp. 50-54, 2009.

[18] K.A. Delic \& J.A. Riley, "Enterprise Knowledge Clouds," Next Generation Km Syst. Int. Conf. Inform., Process, Knowledge Management, Cancun, Mexico, pp. 49-53, 2009.

[19] J. A. Mendez and E. J. González, "Implementing Motivational Features in Reactive Blended Learning: Application to anIntroductory Control Engineering Course", IEEE Tran sactions on Education, Volume: PP, Issue: 99, 2011.

[20] S. Ouf, M. Nasr, and Y. Helmy, „An Enhanced E-Lear ning Ecosystem Based on an Integration between Cloud Computing and Web2.0", Proc. IEEE International Symposium on Signal Processing and Information Technology (ISSPIT), pages 48-55, 2011.

[21] D. Chandran and S. Kempegowda, „Hybrid E-learning Platform based on Cloud Architecture Model: A Proposal", Proc. Int ernational Conference on Signal and Image Processing (ICSIP), pages 534-537, 2010.

[22] L. Huanying, "Value and understanding for cloud com puting based on middleware", Programmer, 2010.05. pp.68,69.

[23] F. feng, "Cloud-based IT infrastructure of next-gen eration telecom", Mobile Communications, 2010, No. 8, pp.76-79.

[24] Md. Anwar Hossain Masud, Xiaodi Huan, "An E-learning System Architecture based on Cloud Computing", World Academy of Science, Engineering and Technology 622012.

[25] H. Xin-ping, Z. Zhi-mei , D. Jian, "Medical Informatization Based on Cloud Computing Concepts and Techniques”, Journal of Medical Informatics, 2010, Vol.31, No.3, pp.6-9.

[26] NIST, Mell, P. and T. Grance, "The NIST Definition of Cloud Computing", 2011, p. 6.

[27] Hossain , M. M. A. , \& Huang, X. (2012). "An e -learning system architecture based on cloud computing". International Scholarly and Scientific Research \& Innovation,6(2),736-740. 